\title{
PENGEMBANGAN KULINER LOKAL SEBAGAI DAYA TARIK WISATA DI DILI, TIMOR LESTE
}

\author{
Elizabeth Barreto Araujo \\ Prodi Magister Kajian Pariwisata Universitas Udayana \\ Email: elisabet.bareto@yahoo.com
}

\begin{abstract}
The development of tourism industry can provide opportunities for tourism products including culinary in Dili, Timor-Leste. This article aims to identify types of traditional foods, measure the perception of tourists on traditional food and formulate program to develop traditional food as culinary tourism. Data collection for this article used direct field observation, interviews and documentation study, while data analysis used SWOT matrix. The results of this article revealed that in Dili there were several types of traditional food such as Saboko, Tukir, Kulu tunu or Kulu Gisa could be developed as culinary tourism. In regard to tourist perception on traditional food processing while good on quality of traditional food, food cleanliness and quality of restaurant service. Several programs conducted by the government to develop traditional food are human resource quality improvement, creating market for traditional food, identification of potential local products in each district and assessment of traditional foods. The restaurant owners also develop several programs such as menu adjustment, creativity in traditional food processing, and promotion.
\end{abstract}

Keywords : development, traditional food, attraction, culinary tourism, Timor Leste.

\section{Pendahuluan}

Pariwisata sebagai industri perlu dikembangkan karena merupakan sektor penting dalam pembangunan ekonomi suatu negara. Sebagai industri, pariwisata dapat mendorong perkembangan di beberapa sektor perekonomian nasional misalnya (1) peningkatan kegiatan perekonomian sebagai akibat dibangunnya prasarana dan sarana demi pengembangan pariwisata; (2) meningkatkan industri-industri baru yang erat kaitannya dengan pariwisata misalnya transportation dan accommodation; (3) meningkatkan hasil pertanian dan peternakan untuk kebutuhan hotel dan restoran, sebagai akibat semakin banyak orang melakukan perjalanan wisata; (4) memperluas barang-barang lokal untuk lebih dikenal oleh dunia 
internasional termasuk makanan dan minuman 5) membantu mambangun daerah-daerah terpencil yang selama ini tidak tersentuh pembangunan (Wahab dalam Yoeti, 2008:36).

Timor Leste mulai mengembangkan potensi pariwisatanya sebagai daya tarik, walaupun jumlah kunjungan belum banyak. Sementara promosi terus dihgalakkan, diharapkan ke depan kunjungan bisa meningkat. Perkembangan pariwisata Timor-Leste bisa dilihat pada jumlah kunjungan yang disajikan pada Tabel 1.

Tabel 1. Jumlah Kunjungan Wisatawan tahun 2007-2013

\begin{tabular}{cc}
\hline Tahun & Jumlah Kunjungan Wisatawan \\
\hline 2007 & 6.176 \\
2008 & 8.927 \\
2009 & 13.552 \\
2010 & 29.098 \\
2011 & 38.341 \\
2012 & 25.215 \\
2013 & 43.962 \\
\hline
\end{tabular}

Sumber: Mentri Pariwisata Seni dan Kebudayaan, 2015.

Tabel 1 menunjukkan bahwa meningkatnya kunjungan wisatawan secara signifikan sehingga menjadi tuntutan bagi pemerintah untuk memfasilitasi pertumbuhan industri pariwisata dalam rangka mencapai kepuasan, dengan memperbaiki infrastruktur pada setiap Daerah Tujuan Wisata (DTW), termasuk Bandar udara Dili dan perluasan jaringan telekomunikasi, industri perhotelan, dan program terkait dengan pengembangan wisata kuliner. Kuliner merupakan salah satu jenis wisata yang mengedepankan makanan lokal, yang memiliki peran penting dan akan menjadi pengalaman baru bagi wisatawan. Pengalaman baru dapat diperoleh wisatawan berupa keunikan cita rasa, penggunaan bumbu tradisional, cara pengolahan serta kemasan yang bersifat tradisional.

Penyediaan fasilitas makanan dan minuman tentu saja tidak dapat dipisahkan dari kebutuhan wisatawan sebagai bagian dari produk wisata. Dengan alasan bahwa keinginan untuk memberi kepuasan bagi wisatawan, membuat para pengusaha yang bergerak dalam penyediaan makanan dan minuman melakukan berbagai usaha untuk menyediakan berbagai hidangan yang sesuai dengan "taste" wisatawan yang datang dari berbagai negara. Dengan gencarnya usaha untuk memperkenalkan makanan dan minuman tradisional membuat wisatawan mancanegara mulai menyesuaikan dan menyukai makanan dan minuman khas dari tempat wisata yang mereka kunjungi (Prasiasa, 2013:6).

Artikel ini membahas topik pengembangan terhadap wisata kuliner pada industri pariwisata, dengan mengkaji beberapa jenis makanan khas 
Timor-Leste yang berpotensi sehingga dikembangkan sebagai pendukung daya tarik wisata. Secara spesifik, artikel ini akan menelusuri pengembangan makanan tradisional sebagai daya tarik wisata kuliner di Dili, dan mengangkat makanan khas Timor-Leste secara umum. Artikel ini diharapkan dapat memberikan kontribusi kepada instansi terkait, khususnya pada pihak pengolah makanan tradisional di industri pariwisata dan pihak pemerintah terkait dengan pengembangan wisata kuliner sebagai khas dan identitas negara Timor-Leste, memiliki kuliner yang beragam dan adapun beberapa jenis makanan yang saat ini sudah terpopuler baik di kalangan masyarakat maupun wisatawan, di antaranya seperti Saboko, Tukir, dan Ketupa yang memiliki cita rasa tersendiri. Kenyataannya bahwa sejumlah makanan khas yang ada belum berhasil menjadi makanan tuan rumah atau makanan yang dapat memperkenalkan ciri khas dan identitas negara. Untuk itu, perlu dikembangkan agar makanan khas Timor-Leste dapat dikenal oleh dunia pariwisata seperti di negara lain. Artikel ini disusun untuk menjawab pertanyaan-pertanyan berikut. Pertama, Apakah jenis-jenis makanan tradisional yang dapat dikembangkan sebagai daya tarik wisata kuliner? Kedua, bagaimanakah persepsi wisatawan terhadap makanan tradisional? Ketiga, bagaimanakah bentuk program pengembangan makanan tradisional sebagai daya tarik wisata kuliner di Dili? Secara praktis, artikel ini diharapkan menentukan beberapa produk wisata kuliner yang perlu dikembangkan dan menambah verifikasi daya tarik wisata kuliner.

\section{Teori dan Metode}

Teori yang digunakan untuk memecahkan pokok permasalahan adalah teori gastronomi merupakan seni atau ilmu terhadap kenikmatan sebuah makanan dan minuman (Scarpato, 2002:36). Teori tersebut digunakan untuk mengkaji potensi jenis-jenis makanan tradisional yang dapat dikembangkan sebagai daya tarik wisata kuliner, termasuk keunikan dalam hal pengolahan dan penyajian makanan. Selajutnya teori persepsi terhadap produk atau jasa berpengaruh terhadap tiga faktor, yaitu (1) tingkat kepentingan pelanggan, (2) kepuasan pelanggan, dan (3) nilai. (Rangkuti, 2003). Teori tersebut dipergunakan untuk menganalisis sejauh manakah persepsi wisatawan terhadap makanan tradisional di Dili, Timor-Leste. Dan teori pengembangan produk Pada dasarnya adalah usaha yang dilakukan secara sadar dan bersama untuk memperbaiki produk yang sedang berjalan atau menambah jenis yang sudah ada. Pengembangan produk menurut Kotler dan Amstrong (2004:339) adalah pengembangan produk original, perbaikan produk, modifikasi produk dan merek baru yang perusahaan kembangkan, departemen riset dan pengembangannya sendiri. Teori ini dipergunakan untuk mengkaji strategi pengembangan makanan tradisional sebagai daya tarik wisata kuliner di Dili, Timor-Leste. Pengajian terhadap 
pengembangan produk makanan tradisional menjadi penting dilakukan karena makanan tradisional sabagai salah satu produk yang akan ditawarkan kepada wisatawan dan diharapkan dapat menjadi daya tarik wisata kuliner.

Teknik pengumpulan data dilakukakan dengan mengunakan observasi, wawancara mendalam, kuesioner, dan dokumentasi. Teknik analisis menggunakan analisis deskriptif kualitatif dan analisis SWOT (Strength, Weakness, Opportunities Dan Threats).

\section{Potensi Kuliner Timor Leste untuk Daya Tarik Wisata}

Dili merupakan ibu kota negara Timor Leste, terletak di sepanjang pantai utara Pulau Timor Leste, sekitar 60 kilometer ke arah Timur dari perbatasan dengan Timor Barat. Di samping jalan pesisir dan pantainya, Distrik ini menjangkau sampai daerah bergunung-gunung yang tidak datar. Luasnya ibu kota ini sekitar $170 \mathrm{~km}^{2}$. Distrik Dili mencakup Pulau Atauro, yang sekitar 30 kilometer ke arah utara pantai Kota Dili. Pada arah selatan Dili perbatasan dengan Distrik Aileu, ke arah barat, Distrik Liquica dan ke arah timur, Distrik Manatuto.

Pengamatan secara langsung Dili memiliki potensi dan daya tarik yang beragam di antaranya adalah potensi alam, budaya dan pertanian. Adapun daya tarik wisata yang sudah populer seperti wisata spiritual patung Paus Yohanes II dan patung Kristus Raja (Cristo Rei), bangunan bersejarah seperti kantor pemeritah (Palacio Governo), Museum da Registensia TimorLeste, Monument Jardin Farol, Gedung Negara, Arte moris, dan Simiterio Santa Cruz. Objek dan daya tarik wisata alamnya seperti Dolok Oan, Pantai Pasir Putih (Area Branca), Pantai Kelapa, Largo Lecidere, Pulau Atauro dan Danau Tiga (Tasi Tolu).

\subsection{Jenis Makanan Tradisional yang Teridentifikasi}

Terkait dengan pengembangan daya tarik wisata kuliner di Timor-Leste khususnya di Dili, teridentifikasi beberapa produk wisata kuliner yang perlu dikembangkan seperti:

\section{1) Saboko}

Saboko adalah salah satu jenis makanan tradisional yang memiliki ciri khas dan rasa yang unik dengan proses pengolahan secara grilled atau memanggang. Wisatawan lebih minat memilih saboko sebagai salah satu kuliner yang dapat dicicipi ketika mengunjungi Timor-Leste khususnya di Dili, karena harga dari makanan tersebut dianggap termasuk murah bagi wisatawan mulai dari $\$ 20-\$ 35$ dollar dengan porsi untuk 4 orang atau lebih dari 4 orang. Lihat (Gambar 1) Penyajian makanan Saboko di industri pariwisata khususnya restoran Golden Star, sesuai dengan biaya yang dikeluarkan oleh wisatawan. Proses pengolahan makanan ini membutuhkan waktu selama 15 sampai 17 menit. 


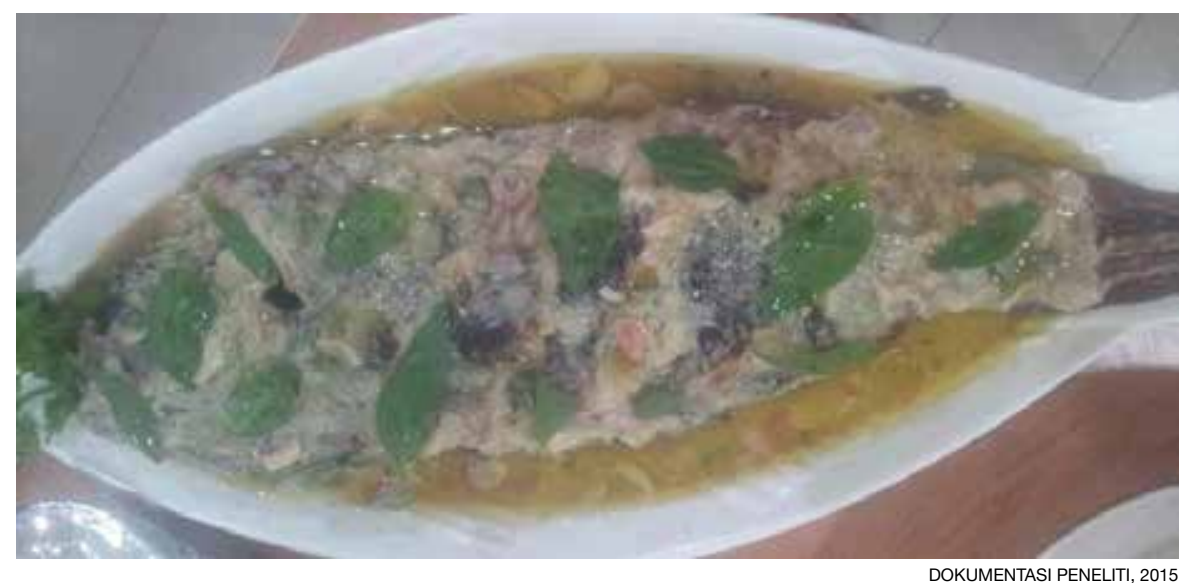

Gambar 1. Penyajian Saboko di restoran Golden Star.

\section{2) Tukir}

Tukir adalah salah satu jenis makanan yang dimasak dari bambu dengan cara memanggang. Selain beras merah, daging juga bisa diolah dari bambu. Tukir memiliki sejarah bahwa pada zaman dahulu para leluhur menggunakan bambu sebagai alat memasak. Saat ini, tukir termasuk salah satu jenis makanan khas yang diminati oleh wisatawan. (Gambar 2) penyediaan jenis makanan yang hanya tersedia di restoran atau rumah makan tertentu saja, di antaranya adalah L'auberigne Restoran, Golden Star, dan Novu Turismo dengan proses pengolahan, harga, porsi, dan penyajian ditentukan secara berbeda dari masing-masing pihak pengelola restoran.

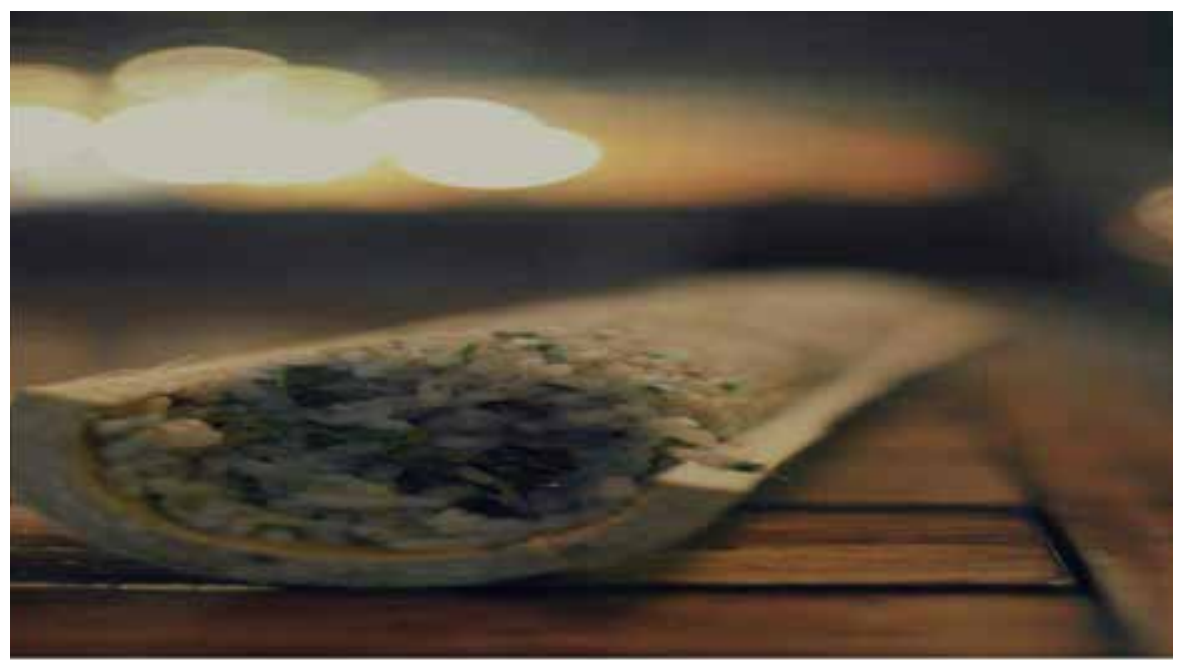

Gambar 2. Tukir

SEJAR DA COSTA. 


\section{3) Kulu tunu atau kulu gisa}

Jenis makanan seperti kulu tunu atau kulu gisa sebagai salah satu jenis makanan yang berasal dari distrik Baucau. (Gambar 3) jenis makanan ini, hanya tersedia di restoran L'auberigne. Dengan alasan bahwa selain menawarkan makanan khas yang tersedia di Dili, perlu juga ditawarkan makanan khas yang berasal dari berbagai daerah, khususnya daerah terpencil dalam rangka untuk memperkenalkan dan melestarikan jenis makanan tradisional yang ada di negara Timor-leste sebagai identitas negara. Diperkuat hasil wawancara dengan kepala dapur di L'auberigne restoran menjelaskakan bahwa:

"Restoran L'auberigne tidak hanya menawarkan menu modern saja, tetapi menawarkan makanan lokal juga yang berasal dari berbagai daerah sebagai menu spesial karena saat ini, makanan khas Timor-Leste semakin dikenal dan diminati oleh wisatawan bukan hanya makanan khas di Dili saja tetapi dari tiap distrik termasuk Baucau" (Wawancara, 22 juni 2015).

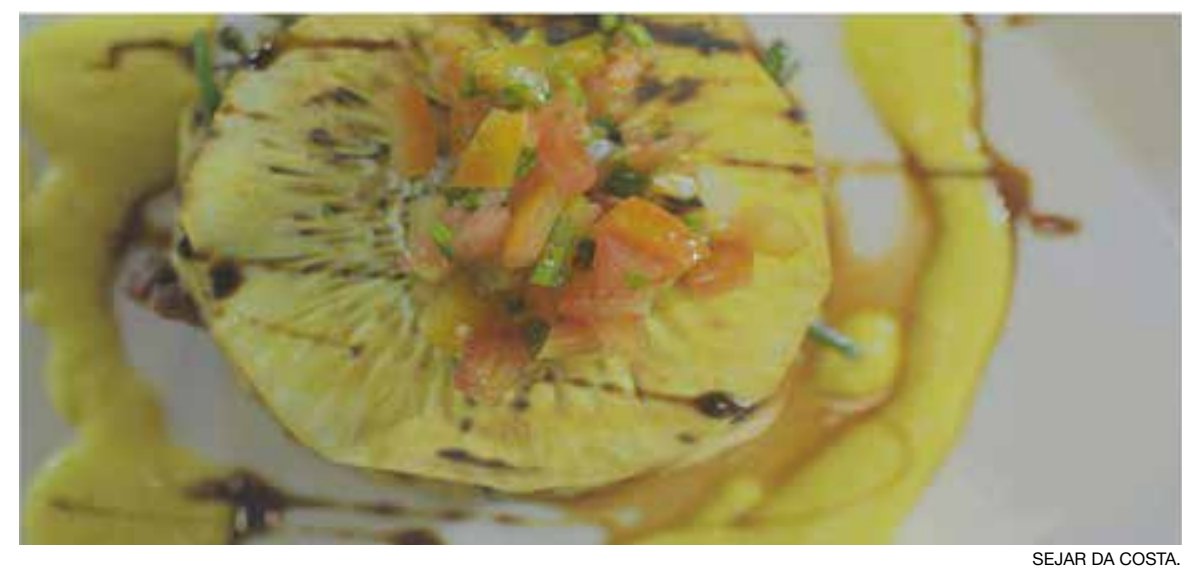

Gambar 3. Kulu Gisa

Cara pengolahan ketiga jenis makanan tersebut, khususnya di restoran Golden Star dan Novu Turismo, dan Restoran L'auberigne biasanya dimulai dari tahap pemilihan bahan-bahan mentah, tahap persiapan hingga ditahap proses pengolahan. Bumbu dasar yang digunakan untuk proses pengolahan makanan tradisional berasal dari hasil pertanian dan perikanan.

\subsection{Persepsi Wisatawan terhadap Makanan Tradisional di Dili}

Persepsi wisatawan asing dan wisatawan domestik yang secara langsung pada lokasi penelitian khususnya direstoran Golden Star dan Novu Turismo terhadap pengembangan makanan tradisional di Timor-Leste dari berbagai aspek, seperti tampak pada Tabel 2: 
Tabel 2. Persepsi Wisatawan terhadap makanan tradisional di Restoran Golden Star dan Novu Turismo

\begin{tabular}{|c|c|c|c|c|}
\hline Persepsi & $\begin{array}{l}\text { Penilaian } \\
\text { wisatawan }\end{array}$ & $\begin{array}{c}\text { Jumlah } \\
\text { wisa- } \\
\text { tawan }\end{array}$ & $\begin{array}{c}\text { Present } \\
\text { (\%) }\end{array}$ & $\begin{array}{c}\text { Total } \\
\text { kunjungan } \\
\text { wisatawan }\end{array}$ \\
\hline 1. Kualitas Makanan Tradisional & Sangat Baik & 10 & $50 \%$ & \\
\hline 2. Porsi Makanan Tradisional & Sangat Baik & 10 & $50 \%$ & \\
\hline 3. Variasi Menu & Baik & 9 & $45 \%$ & \\
\hline 4. Kebersihan Makanan Tradisional & Sangat Baik & 10 & $50 \%$ & \\
\hline 5. Penyajian Makanan Tradisional & Sangat Baik & 8 & $40 \%$ & \\
\hline 6. Harga Makanan Tradisional & Baik & 13 & $65 \%$ & \\
\hline 7. Promosi Makanan Tradisional & Tidak Baik & 8 & $40 \%$ & 20 \\
\hline 8. Kualitas Pelayanan Staf di Restoran & Baik & 8 & $40 \%$ & \\
\hline 9. Suasana Restoran & Baik & 7 & $35 \%$ & \\
\hline 10. Penyediaan Hiburan di Restoran & Baik & 6 & $30 \%$ & \\
\hline
\end{tabular}

Sumber: Hasil Penelitian 2015.

Tabel 2 menunjukkan bahwa persepsi "Sangat Baik" terhadap kualitas makanan tradisional, porsi, penyajian makanan, dan kebersihan makanan tradisional dianggap sangat bersih. Selain itu, adapun persepsi "Baik" terhadap variasi menu direstoran, harga makanan termasuk murah, kualitas pelayanan staf, suasana restoran, dan penyediaan hiburan direstoran. Persepsi "Tidak Baik" terhadap promosi makanan di restoran. Hal tersebut sebagai masukan bagi para pihak pengelola agar promosi yang dilakukan perlu diperhatikan supaya bisa menjadi lebih baik dari yang sebelumnya.

\subsection{Program Pengembangan Makanan Tradisional di Dili, Timor- Leste}

Hasil analisis terhadap faktor internal dan faktor eksternal terkait dengan pengembangan makanan tradisional di Dili, Timor-Leste, diperoleh beberapa faktor kelebihan dan kelamahan terhadap makanan tradisional di Dili yang akan disajikan dalam Tabel 3:

Berdasarkan Tabel 3, Matrik SWOT, dapat dipahami bahwa pengembangan makanan tradisional di Dili berada pada posisi StrengthsOpportunity (SO). Terkait dengan teori Rangkuti (2013: 83) bahwa menciptakan strategi untuk memanfaatkan peluang yang ada, sehingga akan memberikan dampak positif terhadap pengembangan makanan tradisional di Timor-Leste khususnya Dili.

Agar pengembangan makanan tradisional di Dili mampu menjadi tuan rumah sendiri maka, perlu dilakukan program pengembangan, baik bagi pihak pengolah makanan tradisional di industri pariwisata maupun pada pihak pemerintah. Program tersebut seperti: 
Tabel. 3 Faktor Kelebihan dan Kelemahan makanan tradisional di Dili, Timor-Leste.

\begin{tabular}{|c|c|c|}
\hline Faktor Eksternal & $\begin{array}{l}\text { Kekuatan/Strength }(S) \\
\text { 1. Kualitas makanan tra- } \\
\text { disional. } \\
\text { 2. Proses pengolahan } \\
\text { 3. Keunikan cita rasa, aroma } \\
\text { dan tekstur. } \\
\text { 4. Memiliki originalitas } \\
\text { 5. Kesesuaian antara biaya }\end{array}$ & $\begin{array}{l}\text { Kelemahan/Weaknesses }(W) \\
\text { 1. Kurangnya pasar tradision- } \\
\text { al } \\
\text { 2. Kurangnya promosi } \\
\text { 3. Harga bahan lokal cukup } \\
\text { mahal. }\end{array}$ \\
\hline $\begin{array}{l}\text { Peluang Strenght/Opportuni- } \\
\text { ties }(\mathrm{O}) \\
\text { 1. Belum ada persaingan } \\
\text { 2. Kebijakan pemerintah } \\
\text { memperkenalkan identitas } \\
\text { negara dari segi kuliner. } \\
\text { 3. perlu dikembangkan jenis } \\
\text { makanan tradisional. } \\
\text { 4. Memberikan pendapatan } \\
\text { 5. mempromosikan } \\
\text { Timor-Leste khususnya } \\
\text { daerah terpencil yang teri- } \\
\text { kat dengan produk lokal. } \\
\text { 6. Memiliki ciri khas tersendi- } \\
\text { ri. }\end{array}$ & $\begin{array}{l}\text { Strategi Strenght opportunity } \\
\text { (SO) } \\
\text { 1. Mempertahankan identitas } \\
\text { negara. } \\
\text { 2. Mempertahankan kualitas } \\
\text { makanan traisional di Kota } \\
\text { Dili. } \\
\text { 3. Membuka lapangan kerja } \\
\text { bagi para petani. }\end{array}$ & $\begin{array}{l}\text { Strategi Weaknesses (WO) } \\
\text { 1. Meningkatakan kepedulian } \\
\text { 2. Meningkatakan mutu pro- } \\
\text { duk lokal. }\end{array}$ \\
\hline $\begin{array}{l}\text { Ancaman / Threats }(\mathrm{T}) \\
\text { 1. Produk makanan dari daer- } \\
\text { ah atau negara lain. } \\
\text { 2. Perkembangan jumlah } \\
\text { kunjungan wisatawan. }\end{array}$ & $\begin{array}{l}\text { Strategi Strenght Threats (ST) } \\
\text { 1. Bekerja sama antara pihak } \\
\text { pengelola dengan pemerin- } \\
\text { tah serta instansi lainnya } \\
\text { 2. Meningkatkan image, } \\
\text { kualitas, dan keamanan } \\
\text { makanan tradisional di } \\
\text { Kota Dili. }\end{array}$ & $\begin{array}{l}\text { Strategi Weaknesses threats } \\
\text { (WT). } \\
\text { 1. mengontrol harga bahan } \\
\text { lokal. } \\
\text { 2. Menjaga kualitas makanan } \\
\text { tradisional di Kota Dili. }\end{array}$ \\
\hline
\end{tabular}

Sumber: Hasil Penelitian 2015.

\section{Adaptasi Menu}

Pengembangan produk atau kreasi menu restoran sebaiknya dimulai atau diakhiri berdasarkan pada keinginan konsumen (Miner,1996:36). Terdapat berbagai macam bentuk adaptasi menu yang dapat dilakukan seperti menawarkan menu paket dengan menampilkan menu utama. Hal ini diperkuat wawancara dengan chef Sejar da Costa di restoran L'auberigne

"Untuk mempertahankan makanan tradisional di Dili agar tidak hilangnya identitas suatu negara atau sebagai makanan tuan rumah maka perlu dilakukan adaptasi menu dalam hal mengkombinasikan makanan tradisional dan modern dengan menggunakan sistem fusion food. Contohnya Kulu Gisa atau Kulu Tunu (nanka) dengan seafood atau Ikan Saboko dengan sauce"(Wawancara, 22 Juni 2015).

\section{Membuat Penilaian terhadap Makanan Tradisional}

Adapun ide yang disampaikan oleh salah satu pegawai negeri pada Kementerian Pertanian bapak Albino Ribeiro menyatakan bahwa:

"Salah satu strategi yang perlu dilakukan untuk pengembangan makanan tradisional adalah membuat penilaian terhadap makanan tradisional agar 
mengidentifikasi jenis makanan tradisional yang perlu dikembangkan dan dilestarikan sebagai daya tarik wisata kuliner dalam rangka menambah variasi makanan tradisional di Timor-Leste khususnya di Dili” (Wawancara, 1 Januari 2015).

\section{Promosi di Media Masa}

Dalam hal ini, perlu melibatkan media masa dan para chef untuk menulis semacam artikel mengenai berbagai jenis makanan tradisional yang ada di Kota Dili. Semua jenis makanan tradisional yang ada di Kota Dili masingmasing memiliki latar belakang tersendiri. Selain itu, perlu bantuan dari media untuk melakukan kerja sama dengan pihak pengelola agar dapat dipromosikan jenis-jenis makanan tradisional yang ada.

\section{Meningkatkan Kualitas Sumber Daya Manusia}

Sumber daya manusia diakui sebagai salah satu komponen vital dalam pembangunan pariwisata karena sebagai salah satu industri jasa, sikap dan kemampuan staf akan berdampak krusial terhadap pelayanan pariwisata yang diberikan kepada wisatawan yang secara langsung akan berdampak pada kenyamanan, kepuasan, dan kesan atas kegiatan wisata yang dilakukannya (Pitana, 2009:72). Kualitas sumber daya manusia sangat penting dalam meningkatkan kemampuan dan profesionalisme, pemerintah perlu untuk memberikan pelatihan khusus yang terampil dalam bidang industri pariwisata. Hal ini diperkuat hasil wawancara dengan Ibu Maria Ernestina sebagai Direktur Industri dan Produk Lokal pada Kementrian Pariwisata dan Kebudayaan menyatakan bahwa:

"Demi meningkatkan kualitas sumber daya manusia yang spesifik dalam bidang food product maka saat ini sedang merencanakan untuk mengadakan pelatihan khusus mengenai pengembangan makanan tradisional di Dili. Dengan alasan bahwa untuk dapat mempertahankan dan melestarikan jenis makanan tradisonal yang ada” (Wawancara, 9 Juni 2015).

\section{Membuka Pasar Tradisional}

Pasar adalah tempat yang mempunyai unsur sosial, ekonomis, kebudayaan, politis dan lain-lain, tempat pembeli dan penjual (atau penukar tipe lain) saling bertemu untuk mengadakan tukar- menukar (Belshaw dalam Suprapto, 1988). Dalam hal ini belum tersedianya pasar tradisional yang secara khusus menawarkan produk-produk lokal, dan berbagai jenis makanan tradisional yang ada di Kota Dili, kepada wisatawan yang mengunjungi daerah tujuan wisata. Saat ini pihak pemerintah khususnya di bidang kepariwisataan sedang berusaha untuk membuka pasar tradisional agar dapat menawarkan berbagai jenis makanan tradisional dan produk lokal pada wisatawan yang akan mengunjungi Dili.

\section{Identifikasi Potensi Produk Lokal pada Tiap Distrik}

Dalam identifikasi potensi produk yang ada, pada tiap distrik dapat diketahui bahwa adanya produk lokal yang perlu lestarikan. Hal ini diperkuat 
dengan hasil wawancara dengan salah satu pegawai negeri pada Kementrian Pertanian Albino Ribeiro bahwa:

"Untuk mempertahankan jenis makanan tradisional yang ada di negara Timor-Leste, saat ini sedang melaksanakan kegiatan food crops yaitu mengidentifikasi berbagai jenis makanan lokal pada tiap distrik yang perlu dikembangkan agar masing-masing daerah memiliki makanan khas yang dapat mewakili distrik sendiri dengan kata lain one village one product”(Wawancara, 1 Juni 2015).

7. Kreatif dalam mengolah sebuah makanan

Kreativitas adalah kemampuan seseorang untuk mencipta yang ditandai dengan originalitas dalam berekspresi yang bersifat imajinatif (Webster dalam Anik Pamilu, 2007:9). James J. Gallagher (dalam Yeni Rachmawati, 2005:15) mengatakan bahwa:

"Creativity is a mental process by which an individual crates new ideas or products, or recombines existing ideas and product, in fashion that is novel to him or her".

Artinya kreativitas merupakan suatu proses mental yang dilakukan individu berupa gagasan ataupun produk baru, atau kombinasikan antara keduanya yang pada akhirnya akan melekat pada dirinya. Penjelasan oleh wawancara dengan pihak pengelola restoran Golden Star Fernando Lay menyatakan bahwa:

"meningkatkan mutu kualitas makanan tradisional serta dapat bersaing dengan makanan lainnya maka sebagai kepala dapur atau chef harus mampu dalam mengkreasikan sebuah menu yang dapat menarik minat wisatawan, maka dari itu para kepala dapur harus kreatif dan mampu menciptakan sebuah menu khususnya menu lokal agar dapat bersaing dengan makanan lainnya" (Wawancara, 10 Juni, 2015).

\section{Promosi}

Promosi adalah sejenis komunikasi yang memberi penjelasan dan meyakinkan calon konsumen mengenai barang dan jasa dengan tujuan untuk memperoleh perhatian, mengingatkan, dan meyakinkan calon konsumen (Buchari, 2006:179). Promosi yang dilakukan oleh pihak restoran mengenai makanan tradisional di Dili melalui program slow food, koko sabour, koko lokal, kompetisi lomba masak, pameran, dan melalui media.

\section{Simpulan Dan Saran}

Berdasarkan uraian di atas, disimpulkan bahwa pengembangan makanan tradisional di Dili memberikan kontribusi terhadap keberlanjutan pariwisata di Timor-Leste. Teridentifikasi jenis makanan tradisional yang perlu dikelola dan di kembangkan sebagai daya tarik wisata kuliner, dapat dilihat dari segi 
proses pengolahan, percampuran bumbu-bumbu, dan proses penyajian yang secara tradisional. Adapun persepsi "Baik" terhadap kualitas makanan tradisional, porsi makanan, variasi menu, kebersihan makanan, dan harga makanan. Terkait dengan analisis SWOT terhadap pengembangan makanan tradisional di Timor-Leste, khususnya Dili menunjukkan bahwa posisi makanan tradisional berada pada posisi Strengths-Opportunity (SO). Maka, perlu dilakukan program pengembangan dalam rangka untuk memafaatkan kekuatan dan peluang yang ada di antaranya adalah: adaptasi menu, membuat penilaian terhadap makanan tradisional, melibatkan media masa, meningkatkan kualitas sumber daya manusia, membuka pasar tradisional, mengidentifikasi potensi produk lokal pada tiap Distrik, Kreatif dalam mengolah sebuah makanan dan promosi.

Dalam artikel ini, ada beberapa hal yang dapat dijadikan saran untuk melakukan penelitian lebih lanjut, di antaranya adalah: Pada pihak pengelola makanan tradisional restoran, khususnya restoran Novu Turismo, Golden Star dan L'auberigne agar tetap optimis dalam mengembangkan makanan tradisional pada masa yang akan datang serta dapat memberikan informasi lebih luas berkaitan dengan pengembangan makanan tradisional; Para akademisi atau peneliti selanjutnya, pengembangan makanan tradisional sebagai daya tarik wisata kuliner ini sangat perlu untuk dilanjutkan sebagai salah satu warisan budaya yang bersifat intangible. Aspek-aspek yang perlu direkomendasikan untuk diteliti lebih lanjut adalah penetapan standarisasi makanan tradisional, melakukan survei terhadap produk lokal di setiap daerah, khususnya daerah terpencil dan kualitas sumber daya manusia yang terampil dalam bidang industri pariwisata. Karena dengan adanya pengembangan terhadap makanan tradisional yang relevan dan tepat untuk diimplementasikan ketika dirangkum dengan baik maka diharapkan menjadi salah satu acuan bagi pihak pemerintah dalam mengambil kebijakan pada bidang makanan tradisional sebagai daya tarik wisata kuliner di Dili.

\section{Ucapan Terima Kasih}

Penulis mengucapkan terima kasih yang sebesar-besarnya kepada Prof. Dr. I Wayan Ardika, M.A sebagai pembimbing I, Dr. Dewa Putu Oka Prasiasa, A.Par. MM sebagai pembimbing II para penguji Dr. Ir. Syamsul Alam Paturusi, MSP., sebagai Sekretaris Program Studi Magister Kajian Pariwisata Universitas Udayana, Dr I Nyoman Madiun, M. Sc dan Prof. Dr. I Nyoman Kutha Ratna, SU atas arahan dan masukan sehingga artikel ini terwujud tepat pada waktunya. ucapan terima kasih juga kepada Ketua Program Studi Magister Kajian Pariwisata Universitas Udayana Prof. Dr. I Nyoman Darma Putra, M. Litt., atas saran dan koreksi terhadap artikel ini.

Ucapan terima kasih juga kepada bapak Estanislau S. Saldanha Mtech, sebagai mantan rektor Dili Institute of Technology, Rektor Dili Institute of 
Technology Manuel F. da C. Vong PhD, Direktur School of Tourism And Hospitality Managemenet Agustinus N. Seran S.Pd., M.Si serta semua dosen dan staf Dili Institute of Technology atas dukungan, bimbingan baik secara material maupun secara moral. Ucapan terima kasih juga kepada keluarga besar khususnya Kedua orang tua tercinta José Manuel Araújo dan Felizarda Ornai Barreto, serta Teman seperjuangan angkatan 2015 yang tidak bisa disebutkan satu persatu.

\section{Daftar Pustaka}

Alma Bucharin, H. 2006. Pemasaran Dan Pemasaran Jasa. Bandung: Alfabeta.

Dino. 2014. Geografi Pariwisata Timor-Leste [cited 2014 Des. 11] available from:http://dinoburumagimata.blogspot.com/2014/o9/geografi-pariwisatatimor-leste-by-dino_55.html.

Fandy, Tjiptono. 2006. Manajemen Pelayanan Jasa. Jogyakarta: Andi.

Iklan online 2014. (serial online), Timor Leste Prioritaskan Pembangunan Pariwisata [cited 2014 Des. 11] available from:http://www.pikiranrakyat. com/node/290587/.

Kotler dan Amstrong. 2004. Prinsip- prinsip Marketing, Jakarta: Salemba Empat. (Edisi Ketujuh).

Margareta and Edwin. 2012. Analisa Pengaruh Food Quality And Brand Image Terhadap Keputusan Pembelian. Jurnal management pemasaran. Vol 1, no 1. (2012) hal. 1-6.

Miner, J.B 1996. Role of Entrepreneurial Task in Growth Of Technologycally Innovativ Firm. Journal Applied Psychology. Vol. 74 No. 4.p.554-560.

Pamilu, Anik. 2007. Mengembangkan Kreativitas dan Kecerdasan. Yogyakarta: Buku Kita.

Pitana, I Gede dan I Ketut Diarta. 2009. Pengantar Ilmu Pariwisata. Yogyakarta: Penerbit Andi.

Prasiasa, Dewa Putu Oka. 2013. Destinasi Pariwisata Berbasis Masyarakat Penerbit: Salemba Humanika.

Rangkuti, F. 2003. Measuring Customer Satisfaction, teknik mengukur dan strategi meningkatkan kepuasan pelanggan plus analisis kasus PLN-JP, Jakarta: Gramedia Pustaka Utama.

Rangkuti, F. 2013. Analisis SWOT Teknik Membedah Kasus Bisnis. Jakarta: PT. Gramedia Pustaka Utama.

Scarpato, Rosario. 2002b. 'Gastronomy Studies in search of Hospitality' in Journal of

Hospitality and Tourism Management, Vol. 9, No.2, June 2002, p.1-36.

Suprapto. 1988. Bertanam Kedelai. Jakarta: Penebar Swadaya.

Yeni Rachmawati. 2005. Definisi Kreativitas: Strategi Pengembangan Kreativitas. Jakarta: Depdikbud.

Yoeti, Oka A. 2008. Perencanaan dan Pengembangan Pariwisata. Jakarta: Pradnya Paramita. 


\section{Profile Penulis}

Elizabeth Barreto Araujo, BBus adalah mahasiswa Magister Kajian Pariwisata di Universitas Udayana Denpasar. Menyelesaikan program Strata (S1) di universitas Dili Institute of Technology dalam bidang perhotelan dan memiliki pengalaman bekerja sebagai asisten dosen di Universitas Dili Institute of Technology. 